\title{
Aguu: From Acholi Post War Street Youth and Children to 'Criminal Gangs' in Modern Day Gulu City, Uganda
}

\author{
Shai André Divon ${ }^{1, *}$ and Arthur Owor ${ }^{2}$ \\ ${ }^{1}$ Norwegian University of Life Sciences (NMBU), Ås, Norway \\ ${ }^{2}$ Centre for African Research, Gulu City, Uganda
}

Corresponding author: shai.divon@nmbu.no; Phone: +47 67231351

Submitted: 19 August 2020 | In revised form: 21 October 2020 | Accepted: 7 January 2021 |

Published: 24 February 2021

\begin{abstract}
This paper analyses the origin and evolution of the Aguu, a group of street youth/children labelled as a criminal gang operating in the streets of Gulu, Uganda. Based on a series of interviews, focus group discussions, participant observations, archival work and literature review, the paper traces the origin of the Aguu to the conflict in Northern Uganda, and describes the transformation of the Aguu from street youth/children linked to war and displacement to their present day labelling as 'criminal gang'. Anchored in an analysis based on Assemblage Theory, this paper demonstrates the complexity, multiplicity and fluidity of the Aguu identity as a group whose inception and evolution, both internal and external, occurs through a process of relationship between social, political, economic and infrastructural changes linked to war, culture, aid and politics, affecting present day security discourses in Gulu, Uganda.
\end{abstract}

Keywords: Africa; assemblage; crime; cities; development; gangs; post-conflict; security; street youth

\section{Introduction}

In July 2014 Human Rights Watch released a report titled 'Where do you want us to go?', dealing with abuses against street children in Uganda. The report stated that: 'Children living on the streets... throughout Uganda's urban centres face violence and discrimination by police, local government officials, their peers, and the communities in which they work and live' [1]. In January 2019, Christine, the daughter of Bishop Nelson Onono Onweng of the Northern Uganda Diocese, was ambushed and stabbed to death in Gulu, the principal town of Northern Uganda, and one of the most important business and commercial hubs of the region [2]. During the funeral, the Deputy Speaker of the Ugandan Parliament, Honourable Jacob Oulanyah said: 'What are we doing in our households and communities to ensure that we raise children who respect lives? It saddens me that young people are the ones killing today'. The murder of Christine Anyeko was carried out by 'street goons' [3], or, as they are dubbed in the local youth language in Gulu: the Aguu.

The local 'youth language' in Gulu is an Acholi-based linguistic practice called the Leb pa Bwulu [4]. The language was established by youth who found themselves in the streets during and after the period of the civil war between the Ugandan People's Defence Force (UPDF) and the Lord's Resistance Army (LRA) [5]. The Aguu, as they initially referred to themselves, is a term that denotes an association with a socially isolated group struggling to subsist within the pre-established norms, conventions, and rules of society as they are defined in the context of Northern Uganda, Gulu municipality, and the Acholi ethnic group. Lit- 
erally translated, the term Aguu is a reference to people 'who would do anything to get by' [6].

The Aguu in the streets of Gulu can be conceptualised in a variety of ways. They can be viewed as children and youth, victims of dire circumstances, that find themselves living in and/or off the streets of Gulu. They can be viewed as youth/children who made a conscious choice to leave their homesteads for various reasons and head to the streets of Gulu. They can be viewed as individuals who resorted to illicit activities as a livelihood strategy; as thugs who prey on by-passers and snatch their valuables; or as organised gangs that engage in coordinated criminal activities, and as criminals-for-hire, used as pawns in a variety of small and large conflicts for purposes of coercion, punishment, self-interest, or revenge. In a theoretical sense, the Aguu can be conceptualised as a group living on the boundary between what is considered normative and non-normative social behaviour in Acholi society and Gulu town [7].

This article focuses on human (in)security as a function of complex social, cultural and political circumstances in Northern Uganda. The particular emphasis of this article is on the relationship between the Aguu external and internal identity, their labelling as a youth criminal organisation, and a variety of social, security, cultural and political discourses in Gulu town about crime, safety, security and street youth/children. The aim of the article is to highlight the complexity and multiplicity of the Aguu, and the label 'street gang' assigned to them. Based on a series of interviews, participant observation, focus group discussions, and archival work conducted in Gulu between 20182019, undertaken as part of a larger project focusing on community-oriented policing in Northern Uganda [8], this article nuances the local socio-political dynamics around street youth/children in Gulu.

To understand the processes of formation and transformation of the Aguu identity as a part of the socio-political discourses on crime and (in)security in Gulu, this article will proceed as follows: we begin by outlining the intellectual and theoretical framework linking Assemblage Theory to the analysis of youth criminal gangs, and then present the methodology and ethics for this research. We trace the origins of the Aguu and how their identity today is presented by different stakeholders in Gulu. We then introduce the make-up, organisation, leadership, and activities of the Aguu as recounted both by members of the Aguu and by other stakeholders in Gulu. We proceed with an analysis and discussion of the Aguu and the complexity of their shifting identities as part of various discursive and nondiscursive multiplicities linked to crime, human security, and discourses of 'deviance' in Gulu. And finally, we conclude this article with a note on limitations, implications, and future research.

\section{Assemblage, the Aguu, and (In)security in Gulu}

This research was conducted in 2018-2019, while Gulu was undergoing major physical and institutional changes towards achieving the status of a City in Uganda [9]. During that period, when asked about the sources of crime in the streets of Gulu, the police, government officials, and members of the community at large, raised the Aguu and their activities as one of the major sources of insecurity. The designation 'youth street gang' in relation to the Aguu is common in modern day Gulu, and several categories of respondents referred to the Aguu as what seemed to designate a coherent entity which they labelled as (youth/children) 'street gang' and one of the main reasons for crime, disruption, and violence in contemporary Gulu. As the discourses about the Aguu and their identity included references to the civil-war and to street youth and children in the streets of Gulu as a function of the conflict, it became increasingly clear that the meaning of Aguu, as well as the identity of its 'members' is rather multiple and complex.

In this paper, we draw from the work of Deluze and Guattari on Assemblage Theory, and subsequent work on the interpretation and application of the theory by scholars such as DeLanda and Buchanan [10-14], to analyse the formation and re-formulation processes of the Aguu. Assemblage Theory has been applied for the analysis of a wide variety of complex societal contexts, including for the analysis of multiplicity and complexity in security studies [15-17], policy analysis [18], criminology, phenomenology, discourse studies, urban studies, street youth and gangs [19-26].

Before we outline the main tenants of the Assemblage approach, we begin by problematising the concept of the 'gang' as an 'entity' to better understand the challenges around the common labelling of the Aguu as a homogenous group regarded as a 'gang' by various groups of stakeholders in Gulu.

\subsection{Problematising 'Gang'}

The criminologist Don Crewe directs attention towards the fact that the term 'gang' is an essentialisation created by external definitions that objectify and simplify the observance of a an eidos: a surface, an appearance, or a phenomenon ([20], p. 1001). It is often assumed that crime and violence are essential features of a 'gang' [27]. This assumption stems from the dominant scholarship on gangs, mainly conducted in the 1970s on- and to explain and address -street gangs in the United States [28-30]. Gangs were expected to be a major source of insecurity in terms of crime and violence, especially in urban spaces [29,31-34]. As a consequence, when a group is labelled 'a gang', it becomes a 'tautological construction' involving 'the relationship between gangs and violent or otherwise criminal behaviour' ([20], p. 1003). While the assumptions linking gangs to crime and violence have dominated the scholarship on gangs, they have been contested by several scholars who offer more nuanced discourses on such groupings $[22,35,36]$. In a broader sense, 'gang' is a simplified term for a variety of complex social groups. When a social group is labelled 'street gang', it immediately assumes a variety 
of traits including violence, crime and other behaviours that are viewed as social deviance, especially when analysed through various criminological perspectives $[19,22]$. Such perspectives presuppose an ontological reality which lead to constrained analyses of the 'gang'. The Aguu, as an entity labelled 'youth criminal gang' by the police, local leaders, and members of the community, is an example of a such a group with an assumed predetermined identity expressed in the common contemporary discourses in Gulu. In these discourses, the Aguu are essentialised and described with certain properties, functions and causes. Viewing the Aguu in such a way serves a variety of purposes in modern day Gulu, a point we return to in our analysis. But this view of the Aguu does not address the fact that the 'entity' is an assemblage of individuals that become 'Aguu' through internal and external processes. We use the Assemblage approach to conduct a critical analysis of the Aguu, asking, based on the specific situation in contemporary Gulu 'what kind of assemblage would be required to produce it?' ([13], p. 473). To understand the processes that lead to assemblages, it is necessary to flesh out the social, political, cultural, historical and economic forces interacting in a context that not only lead to the creation of groups such as the Aguu, but also govern how these groups evolve and change, how they are viewed and understood by others as a function of complex circumstances, as well as how these groups come to characterise themselves.

\subsection{The Assemblage Approach}

Assemblage Theory offers an approach to social complexity which lays emphasis on multiplicity, fluidity and change in an attempt to resist essentialism and reification that stem from definitions ([11], p. 26). Following Deluze and Guattari [10], Buchanan ([13], p. 463) underlines that 'assemblages explains the existence of a thing in the world'; they are 'structured and structuring'; they 'have a logic, and operational sense...that can be mapped'; and 'always strive to persist in their being' though 'they are subject to forces of change...but ultimately prefer not to change'.

According to DeLanda ([12], pp. 12-20), assemblages are individual entities which have an historical contingent identity. As such, assemblages can be an 'individual person, individual community, an individual organisation, an individual city etc.'. While these entities operate at different scales, they are all viewed as assemblages, hence they have the same ontological status, and therefore can interact directly with each other 'individual to individual'.

Assemblages consist of heterogenous components, such as individual persons, but also the material and expressive objects that comprises communities and organisations. As assemblages can be individual entities on different scales, they can 'become component parts of larger assemblages'. Linked to the problematisation of the 'gang' above, the study of the Aguu as an assemblage focuses on the sui-generis properties and the situational contexts that produces it as an entity ([22], pp. 130-131). On another level, the Aguu as an 'entity' is also a part of an assemblage where a relationship exists with other entities such as the police, local leadership, and communities in the space of Gulu municipality [37], in which they are perceived as a 'gang'. This view of the Aguu as an assemblage with suigeneris properties [38-42], and the Aguu in an assemblage where they are labelled as an homogenised (criminal) entity allows us to analyse the Aguu as 'a purely formal arrangement or ordering that functions as a mechanism of inclusion and exclusion' ([13], p. 465) on both levels. In the assemblage approach, the main question is 'given the specific situation, what kind of assemblage would be required to produce it' ([13], p. 473), or as we apply it to our research, the analysis of what produces the Aguu in Gulu today and their labelling as an entity dubbed 'youth street gang'. This type of analysis allows us to see beyond the superficial appearance of the Aguu as a street gang, and peer into the deep structures of action ([13], p. 467).

As DeLanda ([12], p. 21) indicates, 'assemblages emerge from the interaction between their parts, but once an assemblage is in place, it starts acting as a source of limitations and opportunities for its components'. These are described as processes of territorialisation/de-territorialisation. Territorialisation in assemblages refers to the processes through which the components of an assemblage are homogenised, or are drawn from a 'homogeneous repertoire', but may also refer to the spatial boundaries of the whole ([12], p. 22). Deluze and Guattari [10] assert that these processes are anchored in the natural desire of individuals to 'become', and their ability to imagine a future based on that desire, especially in relation to achieving ontological security ([20], pp. 1006-1007). When applied to social groups, territorialising includes consolidation processes encouraging the formation of norms that create clearer demarcation of an assemblage and increase their capacities ([20], p. 1009).

When applied to 'gang' research these can be viewed as processes that promote 'normalisation and homogeneous meanings, styles, and representation' ([20], p. 16). These processes territorialise the 'gang' and move it towards becoming an entity. Territorialisation processes pertaining to an assemblage often lead to de-territorialisation processes in other assemblages, for example when an individual person breaks with the norms of one group and begins adhering to norms of another group. Processes of de-territorialisation can also arise from conflicts between entities, for example when the police or community engage in efforts to disband (physically and discursively) groups labelled as 'criminal gangs'. In such examples the police and the community move to de-territorialise both the spatial and normative spaces of the 'gang' which are seen to be in tension with the spatial and normative spaces of other assembled entities ([22], p. 129).

\section{Methodology}

This article is based on qualitative data collection conducted in Gulu, Uganda between 2018-2019. It combines primary 
data collection through semi-structured interviews, focus group discussions (FGDs), and participant observation, together with historical and archival data analysis, supplemented by media and social media articles and opinions to flesh out and compare the contemporary popular discourses around the Aguu in Gulu. The objective of the methodology applied in this research is to flesh-out, document and analyse the processes that produce the Aguu as an organised criminal youth gang in Gulu. We use discourses to highlight the characteristics and complexities of particular contexts [43]. The methodology is therefore designed to collect data that allows us to explore historical as well as contemporary social and political trajectories that lead to various perceptions of the Aguu as a source of (in)security, but also how 'people work to secure their lives...individually, collectively and through local state and non-state institutions' [43].

For this purpose, a total of thirty-eight semi-structured interviews were conducted with key informants. Interviews were conducted with local government officials in Gulu, police officials (district and municipality levels; leadership and field levels police officers), community and cultural leaders, members of the community, NGOs, personnel in a juvenile remand centre, street youth, current/former members of the Aguu, and Aguu leadership. We also conducted three FGDs, two with members of the community in two randomly chosen divisions of Gulu municipality [44], and one FGD with members of the Aguu. Each FGD comprised of 5-7 participants. In addition, we conducted participant observation through joining a police patrol in Gulu. Interviews were carried out in English and Acholi, as one of the authors is a native Acholi speaker.

Key informants were selected for participation based on their position and roles in the community. We used a local facilitator to identify current/former members of the Aguu and spoke with members of the Aguu who agreed to participate in this research. The Aguu participants were chosen randomly by the facilitator, based on those who agreed to meet with us and consented to participate in this research. Before we began the research in Gulu, the concept and design were subjected to several tiers of ethical approval, including by the EU commission as a pre-condition for the implementation of the project; an approval by a Research Ethics Committee accredited through the Uganda National Council for Science and Technology (UNCST) as a part of the process for acquiring a research permit in Uganda; and an official approval from the Directorate of Research, Planning and Development of the Ugandan Police Force (UPF). These various bodies reviewed and approved the design of the research, the informed consent forms, the interview guides and the overall architecture of the research project in Northern Uganda.

Following the ethical guidelines issued by the EU, UNCST and UPF, all participants in this research were presented with an informed consent form in English and Acholi. The objective and purpose of this research was outlined and explained to all respondents. Participants were informed that the data collected will be used to write-up and publish an academic article. All participants in this research were informed that their identity will be protected and will not be disclosed. As such, the information based on interviews and FGD is presented in this article in a way that cannot be linked to particular individuals. All participants in this research were legally adults, including all Aguu respondents interviewed during the research. All the respondents in this research consented to participate in this research and to the use of the narratives they provided during this research for academic purposes. No data presented in this article can be directly or indirectly linked to current/past members of the Aguu.

\subsection{The Emergence of the Aguu}

It is difficult to establish with certainty when the term Aguu was coined. The birth of youth languages, such as the $L e b$ pa Bwulu is usually attributed to identity construction [45]. In the case of the Aguu as the original practitioners of the Leb pa Bwulu, the birth of the language seems to be related to 'resistance identity' [46] born out of social exclusion usually associated with stigmatised groups [45]. According to Beall et al. ([47], p. 3072), the processes that lead to the establishment of resistance identities often occur in cities that become 'the eye of the storm' due to conflict. Such processes often occur as consequences of civil wars turning into civic conflicts which arise from 'sense of powerlessness among certain urban groups' and the attempts they engage in to reclaim an identity ([47], p. 3072). The origins of the Aguu (term and group) are directly linked to the civil conflict that devastated Northern Uganda between 1986-2006. The course and implications of the conflict, as well as the response of the international community and subsequent intended and unintended impacts of this response are well documented [48-52]. These accounts serve as a background to the inception of the Aguu. They reveal how the conflict led to a transformation of Gulu from a small provincial town to a main hub during both the war and post-war displacement and re-construction processes [49], filling the streets with tens of thousands of displaced Acholi, eventually leading to a socio-cultural crisis whose effects are still unfolding in present contexts. In his article on Gulu as a town/camp, Branch [49] describes how the transformation of Gulu links to the conditions and processes faced by the displaced population since 1986. He highlights how the nexus between conflict, displacement, and international aid efforts impact the foundations of Acholi culture as well as lead to the growth and transformation of Gulu from a small regional urban centre into a main hub (and eventually a city in present day). If we place the formation and later transformation of the Aguu in relationship to this story, as we do below, then the Aguu can be described as a group assembled and transformed through the interaction between the processes of conflict, displacement, aid, reconstruction, and opportunity.

Throughout the civil war in Northern Uganda, the Acholi 
population have been subjected to civilian control strategies exercised by both the LRA and the UPDF [51]. As the LRA conducted massive attacks against the civilian population, engaged in systematic abduction of women and children, and issued decrees banning movement and forcing the abandonment of settlements [52], large portions of the population sought refuge in the relative safety of the streets of Gulu [49]. The UPDF aggravated population displacement by launching systematic attacks on villages suspected of hosting and collaborating with LRA rebels. This general insecurity peaked in 1995-96 with a series of LRA abductions and massacres. During this period, people were forced to leave their lands and homesteads at night and seek refuge in the streets of Gulu and other places [51]. In October 1996, the government of Uganda introduced the 'Protected Villages' policy, which forced the local population to leave their villages on a forty-eight hours' notice and gather in a number of camps where the UPDF had increased military presence [53] ([54], p. 92). Through this process, Gulu town was transformed overnight to the largest camp in the region [49]. This wartime displacement brought into the streets of Gulu a large and diverse population who lost their access to livelihood. It also brought into Gulu a humanitarian economy, creating important new opportunities for the displaced, sustaining the needs of most people in town [49]. These circumstances carried a significant number of people into the streets of Gulu and exposed them to a changing urban environment, while detaching them from their habitual rural livelihoods. But it was mostly the post-war effects of this massive displacement that led to the current fault lines in Acholi society. These fault lines are results of disruptions caused by the war to land tenure systems and property disputes [55,56], education and disconnection of individuals from culture and community lives $[7,57]$ family breakdown and orphanage [58], experiencing urban/westernised lifestyles and 'corporate culture' ([7], p. 92) [49], massive NGO intervention and a humanitarian economy [59], dependency syndrome [60-62], and changes to 'traditional'/cultural institutions [7].

As thoroughly discussed by Atkinson [63], the Acholi are structured around social institutions including several conventions, norms and previously sanctioned rules around family, community, livelihood strategies, household dynamics, culture, rituals etc. In addition, the Acholi society is established within the sovereign Ugandan State, and as such they incorporate into their ethnic institutions the institutions of the state, including education, law and order, political structures etc. The history of Uganda, the civil war, and the subsequent effects of the massive displacement, violence and trauma, breakdown of habitual livelihood structures, of households, of communities, of culture, and of the state institutions, led to a fundamental modification to the traditional Acholi socio-cultural structures ([7], pp. 314-325). Nevertheless, the Acholi have proven to be resilient, and in the years since the end of the conflict, they have re-established their communities, socio-cultural institutions, and organisation [64], and reintegrated into the governance structures of the
Ugandan State. But some, as the Aguu, have not been fully re-integrated into society through these processes. In the case of the Aguu, the transformations that occurred during- and as a consequence of -the conflict, translated into the formation of an entity after the war, which is viewed today by the Acholi community, leadership, and state institutions in Gulu, over a decade after the war has ended, as a disruptive group. Parts of this group today are associated with distinct emergent institutions such as rules, leadership and (street) language, and members of this group are engaged in a variety of livelihood strategies, many of which defy traditional and state institutions. The original group of Aguu emerged from transformations that are directly linked to the disruption caused by the war to community lives, and the disconnection of some youth/children from their nucleus families and responsible care of adults, sources of livelihood and social frameworks. But the processes of transformation of the Aguu are also linked to new opportunities emerging from these circumstances such as the transformation of Gulu into a major hub, and a variety of subsequent prospects available in the emerging urban environment. The original Aguu, as we describe below, were children and youth exposed to various degrees of trauma, loss, and stigmatisation. Their experiences exposed them to changing urban settings, where they found themselves alone in the streets without direct means of livelihood, and at the mercy of the humanitarian economy established by a large number of domestic and foreign NGOs [59]. These conflict-related processes of disconnection from conventional social constructions and exposure to new physical, cultural, and economic environments is at the foundation of the formation of the original group of Aguu. To better understand these dynamics, we outline below the historical origin of street youth/children labelled Aguu in Gulu, and then move to describe the present-day context.

\section{The Origin of the Aguu}

There are two origins for the initial groups of street youth/children dubbed Aguu in Gulu. The first set of street youth/children came from families who lost access to their lands, uprooted from their communities, separated from their livelihoods due to the conflict, and the 'night commuters' who trekked to camps to seek relative safety and protection from LRA attacks and abductions at night $[65,66]$. An additional consequence of this mass displacement was numerous births of children in IDP camps. Some of these children were orphaned due to the war or sickness of their caregivers; others were abandoned by their parents due to early pregnancies and their inability to provide for their children, as well as stigmatisation against single and young mothers. As a result, many of these children who did not know their parents and had no strong cultural/clan identity, found themselves outside the traditional Acholi social institutions. The second set of street children who found themselves rootless in the streets of Gulu are the former abductees. According to estimates, the LRA abducted be- 
tween 54,000 and 75,000 people, out of which 25,000 to 38,000 were children [67]. These children were exposed to a variety of traumatic circumstances during the war, including separation from their homes, safety, abuse, physical and sexual violence. These children were stigmatised and often punished as collaborators by their communities when they escaped from the LRA or returned after the war [49]. The origination of the street language Leb pa Bwulu as well as the emergence of the term Aguu as a self-designation used by these youth/children to refer to themselves as individuals who belong to a group who would do anything to get by, is attributed to these initial groups of youth/children.

In the years that passed since the conflict subsided in 2006, most of the street children/youth associated with the IDP camps and LRA abductions are now teenagers or young adults. Nevertheless, the Aguu as a group is still present in the streets of Gulu, which begs the question who are the Aguu today? The following section attempts to answer this question based on a series of interviews, participant observation and focus group discussions conducted with current and former members of the Aguu in Gulu, street youth, local leaders, police officials, and the community.

\section{The Aguu in $\mathbf{2 0 2 0}$ as Viewed by the Police, Local Leaders, and the Community}

When you ask people in Gulu today what is Aguu, one of the most common answers is 'useless' children and youth. For most people, Aguu is used as a derogatory term to designate 'good for nothing' troublemaking youth that lives in and off the streets, as well as a reference to youth criminals and prostitutes perceived as the main reason for the high crime rates in Gulu. To better observe the variety of issues on the streets of Gulu, we joined a night-time police foot patrol. The patrol departed from Gulu police station at 8:00 pm and lasted about six hours. We joined a team of three armed and uniformed police officers, led by an Assistant Inspector of Police in civilian clothing accompanied by three local community leaders at the LC1 level [68]. The local community leaders held the position of 'defence secretaries', having the responsibility to ensure local security, assist the local council leader (LC1) and the police on matters of security, and liaise between the community, the local council leader and the police on security matters. During the patrol we observed a large presence of youth and children in the streets of Gulu, including young girls acting as prostitutes, both in the streets and around lodges. In July 2018, police officials in Gulu told us that there are about 300 Aguu in the streets. In January 2019, Patrick Jimmy Okema, the Aswa Region Police Spokesperson was quoted in a news outlet saying that 'at least 100 children still sleep and eat off the streets of Gulu town, seven years after peace returned to the region' [69]. Unofficially, a senior police official informed us in January 2020 that there is a gap between the numbers provided by the police for the 'consumption of the general public' and in reality, the police estimates that there are about 600 Aguu in the streets of Gulu. Below we outline who these Aguu are in the streets of Gulu today as they are described through the lenses of the different groups of stakeholders.

According to the police, the Aguu is a reference to a criminal gang. They consist of 'lazy' youth and children, that broke with family traditions and live in and off the streets; they are seen as rebellious youth/children that engage in acts of petty thievery, organised crime and prostitution. The police associate the leadership of the Aguu today with wartime displaced children and abductees. The Aguu are described by the police as a 'street gang' and they often refer to children and youth labelled Aguu as 'members' of a 'street gang'. A variety of criminal activities are attributed to the Aguu by the police. These include organised robbery of unsuspecting civilians, prostitution, house and business break-ins, and various violent criminal activities that often result in injury or murder of civilians. Police officials often use the term 'terrorise' to describe the Aguu impacts on people in Gulu. They are often described by the police as substance abusers and are accused of committing criminal acts under the influence of alcohol or drugs.

Like the police, community leaders often blame the Aguu for much of the insecurity in the streets of Gulu. The term Aguu is used by community leaders and members of the community as a derogatory term, referring to youth and children that spend their time in the streets, do not behave according to socio-cultural norms, cause trouble and commit crime, and as a term that designates an affiliation with a gang. Several accounts by politicians, the police, community leaders and the Aguu, indicate that Aguu is also a reference to youth/children recruited by local businessmen and politicians to commit illegal acts for profit, to intimidate opponents, exert acts of vengeance, and weaken competition. In these narratives the Aguu are also described as both organised gangs and individuals available for hire.

As indicted by local leaders during interviews, the discourse and subsequent action by political leaders in Gulu in relation to the Aguu play an important role in popular politics and local power competitions for resources. This often translates into more than public rhetoric, and transforms into illegal 'vigilante' action led by politicians and local leaders to rid the streets of Gulu from the Aguu. Many prominent leaders in Gulu 'earned their stripes' by leading groups of 'vigilantes' armed with clubs, in what could be described as mob violence actions against the Aguu to 'fix' the crime problem in Gulu. The current Mayor of Gulu, George Labeja, built his reputation and began his political career by leading groups of vigilantes in violent mob justice actions against 'petty thievery' in Gulu. The Mayor often refers to these actions as part of his political campaign promises to bring security to the streets of Gulu [70-72].

In recent years other political leaders have mobilised groups of people in violent civilian actions against the Aguu [73]. These politicians describe the Aguu as 'groups of organised criminals', 'petty thieves' and a 'major source of insecurity in Gulu town'. Such vigilante actions and episodes 
often result in mob violence that lead to death and injury on both sides, as well as cycles of reprisal actions [70-72]. In April 2019, an LC1 chairperson from Layibi division in Gulu mobilised 40 people armed with clubs and other improvised weapons against the Aguu who were accused of plural break-ins, arson, and robbery in the area. This violent episode led to a reprisal action by the Aguu, prompting a joint police and army intervention which included firing live rounds at the Aguu [74].

Some murders of public servants in Gulu are often initially attributed to the Aguu, but without concrete evidence, such as the murders of Gulu Municipal Deputy Town Clerk John Oola in May 2017, former Gulu University lecturer Andrew Rachkara in June 2014, as well as several media personalities. In interviews with police officials and local leaders, the respondents indicated that some of the reasons for the initial attributions of crimes to the Aguu include: using the Aguu to deviate attention from a political or economic motive for the crime; for political reasons; and because the Aguu are often actually hired to conduct such actions by politicians, businessmen and ordinary people.

In general, community members refer to the Aguu as 'criminals' and 'pests'. They see them as youth/children who 'rebelled' against tradition and culture, broke away from family structures and values, and chose livelihood strategies and lifestyles which are not accepted by Acholi society. Street children/youth today bear the same stigma stamped upon the original group of street children/youth associated with the conflict.

Members of the community often explain the lifestyle of the Aguu in relation to substance abuse. As explained by the police, politicians, and as we observed during our nighttime patrol with the police, alcohol, opium and cannabis consumption are concrete problems in Gulu. Both the community and the police use circular arguments to explain crime and presence of children/youth in the streets in relation to substance abuse. Some explain that street children/youth commit crime because they are under the influence of drugs (so being under the influence is the reason for unruly behaviour); on the other hand, others explain that children/youth commit crime because they need money for drugs and alcohol (so addiction is the motivation for crime). But most respondents also connect the presence of children/youth in the streets of Gulu, and subsequent criminal activity for survival, to boredom, to the conflict, and to the outcomes of the conflict. They link the existence of the Aguu and part of their leadership today to the original groups of street children/youth in Gulu. And they also link the presence of street children/youth who were not directly displaced by the conflict or abducted by the LRA to the outcome of the conflict in a variety of ways: some street children/youth are in the streets today because their parents were affected by the conflict in terms of disruptions of livelihood, inaccessibility to land and property, mental sickness etc. and therefore the children/youth had to leave or flee their houses and families. Another explanation is that street children/youth today were 'exposed' to external influence through the humanitarian economy that persisted in Gulu for almost a decade after the conflict ended (foreigners, NGOs, westerners), and therefore choose to try and pursue an urban lifestyle which is not consistent with Acholi values and/or inspired by foreign influence and imagined opportunities. But they also recognise that some children/youth freely choose the street life for freedom and access to what they believe is 'easy money' through a life of crime. In all the examples given to us above, members of the community, police and local leadership see the Aguu today as deviants. Almost no respondents viewed the Aguu as victims or with compassion [75].

\section{The Structure and Composition of the 'Entity' Aguu in 2020 as Described by those Associated with the Group}

Interviews with contemporary street youth indicate that unlike the original Aguu, not everyone who is labelled as such today is homeless, orphan, rootless, or lives permanently in the streets. In addition, and as expected more than a decade after the end of the civil war, the data below indicates that the presence of many street children/youth in Gulu today is unrelated or not directly related to the conflict in the same way as the original group was.

It is difficult to determine with certainty how many children/youth live permanently in the streets of Gulu today. But the fact that some of those who label themselves or are labelled by others as Aguu are not homeless or street children/youth, indicates that the term has clearly transformed from a description of a specific group linked to the conflict and its outcomes, to denote youth and children that live in and off the streets, and include youth and children that are not necessarily homeless, as well as youth and children that conduct criminal activities and exhibit behaviours that are not considered normative such as break-away from their communities, families, abuse substances, and engage in prostitution.

As indicated in the previous section, various stakeholders have firm opinions about the identity of the Aguu as deviants, but in reality, Aguu is a diverse group. In the following section we describe the nuanced identities of street youth based on various self-descriptions collected through interviews and FGDs with male and female respondents. We outline how they themselves view the various reasons behind why certain youth and children end up in the streets today. We then turn to outline the organisation, leadership, activities, coordination of the street youth/children that engage in organised criminal activities, as well as collusion between such groups, labelled Aguu 'gangs' and stakeholders in Gulu as described by members of these groups during interviews.

Firstly, it is important to recall that the term Aguu was coined by street children/youth as a self-reference. While it is used today as a derogatory reference to street youth/children, it is still used by many street youth/children as a self-reference despite the negative external connota- 
tions, a point we come back to in the analysis below. When we asked street youth why they end up in the streets of Gulu today, several underlying explanations emerge from stories told in interviews:

1. Difficult socio-economic conditions at home and death of parents. Many of the street youth/children today find themselves in the streets of Gulu because they do not get along with their caregivers and are chased away from the household. Some have lost their biological parents during the war and were sent to relatives, who themselves have many children. In some cases, when relatives do not have the means to take care of everyone, some youth/children are forced- or choose -to, leave because of the difficult circumstances at home. Some leave home in an attempt to earn money for the family, or because a caregiver is sick and cannot work or take care of the children. In some cases where there are multiple siblings and difficult livelihood situations, such as very little food or space to live, some choose to leave the household.

2. Children born to formerly abducted or returnees, rejected by families and communities. Some children/youth are born to parents that were directly affected by the war. Some caregivers were traumatised and suffer from mental illnesses, other parents are former abductees and suffer from a variety of conditions. Some contemporary youth/children choose- or were forced -to leave because their parents struggle to reintegrate into society or do not manage to perform as caregivers as a result of trauma and other reasons.

3. Conflict with the law and fear of parents. Some report that they had to run away from home because they got in trouble with the law and/or with their parents. Some told us that they were stealing and had to run away, others were gambling away or spending their school fees or their parents' money and ran away due to fear of their parents' reaction.

4. Thrown out for disciplinary reasons and bad behaviour. Some children/youth were thrown out of their homes by their caregivers due to violent verbal and physical disagreements about actions, lifestyle choices and fighting with their parents.

5. Born in the streets. Some street youth/children were born in the streets. Many were born outside of wedlock as a result of prostitution or other circumstances. Some of these were abandoned by young parents in the street at a very young age and were forced to survive and fend for themselves since. Some of these were born to Aguu parents who could not/did not want to take care of them, others were abandoned by their parents in order to avoid stigma.

6. Searching for excitement and opportunities. Some of the street youth/children say they left their homes by choice, to acquire freedom and an opportunity for a better life and livelihoods, and to seize oppor- tunities for a better/different life in the city. Some began to abuse substances such as drugs and alcohol and went to the streets to try and feed their addiction by stealing and prostitution. Others found themselves in the streets because peers convinced them to seek a better life and freedom. Yet others report they wanted independence and the opportunity to escape from their own cultures and traditions in search for freedom and a better life (sometimes influenced by notions presented by other cultures).

It is important to note that some youth found in the streets of Gulu today are not Acholi and come from afar to seek work and new opportunities. This is often the case with female prostitutes that travel to Gulu which is one of the fasted growing urban centres in Uganda, and the biggest Urban centre in Northern Uganda. These are also labelled Aguu.

For many street youth/children, crime and prostitution are livelihood strategies. The processes that lead to the changes of Aguu from homeless and rootless youth and children linked to the conflict who would do anything to get by, to loosely organised criminal gangs is intimately linked to economic, political and social opportunism of both the street youth/children and other stakeholders in Gulu that contribute to the onset of criminal organisation. Some of our respondents indicate that the organisation of some youth/children beyond opportunistic petty thievery into organised criminal gangs is linked to sponsorship of predatory stakeholders such as scrap dealers, local businessmen, vendors from Kampala, politicians, and others. This narrative was also repeated by local government officials and the police interviewed during this research. According to accounts collected from street youth/children and local leaders in Gulu, the organised criminal endeavours of the Aguu began when local scrap dealers solicited street youth/children in Gulu to locate material, steal and bring it back to scrap yards where they would receive a small payment for their service. Some scrap dealers, especially dealers who came from other locations in Uganda, were not familiar with Gulu town and the Aguu serve as their local eyes and hands to gather scrap and other valuable items to be sold by the scrap dealers for a profit. Other local businessmen, such as mobile phone vendors and lodge owners are also using Aguu to turn a profit. Some mobile phone vendors for example, pay Aguu to steal phones, and then sell them for a profit in their shops. Lodge owners essentially use female Aguu prostitutes by allowing them to bring clients to the lodge and rent out rooms at hourly rates. These activities led to several levels of organisation among street youth/children in Gulu, which in turn led to the formation and organisation of groups, including a system of leadership and rules as described below.

The organisation of several groups of street youth and children in Gulu to carry out coordinated activities, has led to increased sophistication and collusion with various opportunistic sponsors. These operations involve coordination with boda-boda drivers who provide transportation 
services; they involve Aguu prostitutes who provide intelligence or help lure victims to be robbed by the group; and coordination between groups in town and their leadership for organisation, seeking permission to conduct activities across territories, and collection of information to be shared between groups. The Aguu also report that in many cases, break-ins, arson, beating, and sometimes murder are carried by contracts they receive from local businessmen, other members of the community, politicians, and external stakeholders from outside the city of Gulu. Sometimes the Aguu coordinate activities with individual members of the police through bribery to ensure slow or lack of police interference or minimal investigation.

When it comes to the leadership and organisation, information collected during interviews indicate that the Aguu cannot be considered as a single organised criminal group with unified leadership. There are several organised groups which act as more or less coherent street criminal gangs, each with their own leadership structure and set of rules. While Aguu criminal groups often communicate and coordinate between themselves (see below), there are no regular 'leadership' meetings nor an overarching leadership structure.

Street children/youth are organised in various territorial settings. These range from groups who claim territoriality based on streets or areas they live in, or around localities such as industrial areas, pubs and lodges. The Aguu often give nicknames to their territory/group (See Table 1). The police and members of the community at large often view the Aguu as 'cells' operating from localities/areas in Gulu, and in many cases members of the Aguu criminal groups also refer to themselves as belonging to these cells.

The Aguu groups vary in size, activities, and level of organisation. Each group seems to have a leadership structure, where at least one member is considered the main 'go-to' leader. Leadership is based on several qualities, including physical strength, experience in the street, cunningness and most importantly, his or her network. A leader needs to be able to coordinate with other groups and their leaders, with the local community, businessmen, police, politicians, and other stakeholders in order to benefit and protect members of the group. The leaders command respect in the street. They must be able to protect and rescue members of their group if the need arises. Members of the groups follow their instructions.

Many indicated that the members of the criminal Aguu groups do not use real names, and especially do not call their leaders by names. There are many nicknames and titles for various leaders and members. Table 2. presents some examples of nicknames given to leaders and lower ranking members of Aguu criminal groups. Sponsors of the Aguu criminal groups are referred to as 'dons' and are those who buy valuables or contract the groups for various purposes.

Members of the Aguu criminal groups follow a loose set of rules that seem to be designed first and foremost to regulate behaviour between the members, between the members and their leaders, and instruct members on how to behave if they are caught. The existence of rules, as well as their formulation as outlined below, is a clear indication of organisation and coordination. If rules are broken there are several prescribed consequences. Sanctions against violators vary, but respondents report that they may range from corporal punishment to banishment in extreme cases. Table 3 presents some of the different rules and sanctions that various Aguu criminal group members must follow.

Table 1. Examples of Gang Nicknames in Gulu.

\begin{tabular}{ll}
\hline Aguu gang nicknames & $\begin{array}{l}\text { Aguu 'cells' named after } \\
\text { localities }\end{array}$ \\
\hline $\begin{array}{l}\text { 'Gang Pa Oweka' (Oweka's } \\
\text { home) }\end{array}$ & Nakasero \\
'Layibi Go-down' in Layibi & Kanyagoga \\
division & \\
'Te-Gwana' (Pece division) & Layibi \\
'K-Ghosts' (Kanyagoga Ghosts) & $\begin{array}{l}\text { Olayo-ilong } \\
\text { 'Cuk pa Lujwero' (in Pece } \\
\text { division) }\end{array}$ \\
\hline
\end{tabular}

Table 2. Example of nicknames given to Aguu leaders and members.

\begin{tabular}{|c|c|}
\hline Leaders & Lower ranking members \\
\hline $\begin{array}{l}\text { 'Latela' (Acholi word meaning } \\
\text { Leader) }\end{array}$ & $\begin{array}{l}\text { 'Dogos',(from the Swahili word } \\
\text { kadogo-small one) }\end{array}$ \\
\hline $\begin{array}{l}\text { 'Afande' (Swahili word for High } \\
\text { Ranking) }\end{array}$ & 'Younger' \\
\hline $\begin{array}{l}\text { 'Ya Kwanza' (Swahili word for } \\
\text { the first one) }\end{array}$ & 'Buddy' \\
\hline \multicolumn{2}{|l|}{ 'Gadafi' } \\
\hline $\begin{array}{l}\text { 'Cuk pa Lujwero' (in Pece } \\
\text { division) }\end{array}$ & 'Siya' \\
\hline 'Yoyo' & 'Kadogo' \\
\hline 'Mchuzi' & 'Jam boys' \\
\hline ‘Toling' & 'Home boys' \\
\hline $\begin{array}{l}\text { 'Ojoko'(Derived from Acholi } \\
\text { name Ojok) }\end{array}$ & 'Kamule' (street slang) \\
\hline \multicolumn{2}{|l|}{ 'Actor' } \\
\hline \multicolumn{2}{|l|}{ 'Whatsapp' } \\
\hline 'Ladit' (Acholi for Elder) & \\
\hline
\end{tabular}


Table 3. Example of Rules and Sanctions for Aguu Members.

\begin{tabular}{ll}
\hline Rules & Sanctions for breaking rules \\
\hline Never disclose who assigned you to a particular mission. & $\begin{array}{l}\text { If you default on payment for bailing a fellow Aguu you are } \\
\text { expelled/banished; if you show remorse you might be subject to } \\
\text { lighter punishments (usually beaten by cane). } \\
\text { If you disclose who is the buyer of the stolen good you are banished. }\end{array}$ \\
$\begin{array}{l}\text { 'Thou shall not be arrested/caught during an assignment'. } \\
\text { Never divulge details of your location and that of your leader. }\end{array}$ \\
$\begin{array}{l}\text { Always share the loot faithfully with colleagues who accompanied } \\
\text { you on a particular exploit. }\end{array}$ \\
When arrested the leader should help bail you out. \\
Aguu members should contribute money to bail an arrested fellow. \\
If you are caught with stolen goods, never disclose who is the \\
intended buyer. \\
You must not hurt your fellow street kid or leader (this rule is often \\
broken, especially if people are under the influence of alcohol or \\
drugs). \\
You should not report your fellows when arrested. \\
Report mishaps to your leader. \\
New recruits must report to the head of the cell/territory and must be \\
accepted/initiated into the group.
\end{tabular}

Many of the females labelled Aguu are engaged in organised prostitution. Prostitutes are mostly organised around local lodges in Gulu, but are also organised as groups in the streets. While the owners of the lodges do not govern the female prostitutes, it is the owner who supervises the affairs of the lodge and the female Aguu leader. The owner communicates with a 'head lady' who is considered the leader of the Aguu prostitutes operating from a lodge. The 'head lady' is usually a prostitute herself but takes control of most decisions and planning of daily activities. In cases where the girls live together as a group or in the same household, then the 'head lady' collects contributions for food from the other prostitutes daily, as well as rent and other utilities on a monthly basis. The 'head lady' enforces the rules of the lodge and the rules of behaviour for the girls (see below). There is usually a connection between the Aguu prostitutes, the 'head lady', and a male Aguu criminal group leader who is responsible for a group in the area. The male Aguu leader and the 'head lady' meet to discuss security issues, coordination with NGOs and other organisation that provide contraceptive and other health services, as well as coordination of other criminal activities where prostitution is involved such as luring victims and other involvement in planning and implementation of criminal activities. Female Aguu also follow sets of rules and are sanctioned in various ways if rules are broken (Table 4.)

The emergence of rules and mechanisms for punishment points to organisation and structure. The rules as described to us seem to serve four main purposes:

1. Anchor the role and legitimacy of the leader.

2. Create a sense of collectiveness, loyalty and belonging.

3. Protect the members of the Aguu criminal groups and leadership through codes of conduct designed for mutual support, protection, and loyalty.

4. Minimise internal friction and behaviours that can lead to exposure and conflict.

These rules are installed to provide a sense of security, structure and belonging to group members, as well as predictability in terms of outcomes if members do not conform to the established organisation.

It is important to emphasise that not all Aguu engage in criminal activities, and that those who engage in criminal activities also pursue other livelihood strategies. Many find a variety of temporary work opportunities available in the streets, such selling fast food and a variety of other products to commuters in junctions; cleaning, carrying, moving, helping jobs; daily or temporary jobs offered by various contractors and farmers inside and outside Gulu where the Aguu are picked up in locations by contractors based on ad-hoc selection etc. 
Table 4. Example of Rules and Sanctions for Female Aguu Prostitutes.

\begin{tabular}{|c|c|}
\hline Rules & Sanctions for breaking rules \\
\hline $\begin{array}{l}\text { If you fight or quarrel with a client, colleagues or owner of the } \\
\text { premise you are chased away. }\end{array}$ & $\begin{array}{l}\text { You pay a fine of fifty to one hundred thousand shillings, or any } \\
\text { amount decided by the leader. }\end{array}$ \\
\hline $\begin{array}{l}\text { You should not call the man who is a client while on 'duty' your } \\
\text { husband or boyfriend-they are simply clients with no attachment to } \\
\text { you. }\end{array}$ & $\begin{array}{l}\text { You can be chased away by the group leader. } \\
\text { You buy plastic chairs for the lodge. } \\
\text { If you are new you get one warning. }\end{array}$ \\
\hline \multicolumn{2}{|l|}{$\begin{array}{l}\text { Time management is important, and especially when girls need to go } \\
\text { back to where they reside. }\end{array}$} \\
\hline \multicolumn{2}{|l|}{$\begin{array}{l}\text { When moving, one should use trustful Boda-Boda drivers to avoid } \\
\text { mishaps and robbery on the way. }\end{array}$} \\
\hline \multicolumn{2}{|l|}{ You must ensure you are paid before the client leaves. } \\
\hline \multicolumn{2}{|l|}{ No unnecessary loud noises when in the rooms. } \\
\hline \multicolumn{2}{|l|}{ Stealing from colleagues, clients and the lodge is not permitted. } \\
\hline \multicolumn{2}{|l|}{$\begin{array}{l}\text { Identity cards must be submitted to the lodge owners before you start } \\
\text { operations. }\end{array}$} \\
\hline \multicolumn{2}{|l|}{$\begin{array}{l}\text { You should dress decently when not working especially during the } \\
\text { day to avoid stigma, labelling and name calling. }\end{array}$} \\
\hline \multicolumn{2}{|l|}{ Matters related to the group must remain confidential. } \\
\hline Witchcraft and use of herbs in the lodges is not allowed. & \\
\hline
\end{tabular}

\section{Analysis and Discussion}

In every society one can locate discourses alluding to past times when culture and society thrived, and great things were accomplished. In post-war 'Acohliland' these discourses are rather prominent, celebrating a notion of a pre1986 past where 'traditional institutions', 'culture', and 'family values' were respected as the pillars of society. There is no doubt that the war has had a deep impact on Acholi societal institutions and has led to several fault lines within that society. In Gulu, the onset of the processes of change that contributed to the inception of the Aguu as an entity, are linked to the civil war and the circumstances which led to an unusual number of youth/children in the streets of Gulu, disconnected from the habitual environment and social institutions. In parallel, international efforts to assist the civilian population affected by the war coupled with the massive displacement of population, led to both the physical growth and the introduction of new livelihood opportunities in Gulu. It is not surprising that in the years since the war ended, these circumstances accelerated tensions between forces of continuity and forces of change in Acholi society and the state. As summarised by Vorhölter ([7], p. 272), the societal and cultural principles that structured the pre-war Acholi society have been disturbed by the war, but they have also 'been challenged by women and youth, who took over new roles during and after the war'. In addition, the proliferation of 'western' ideas through the heavy involvement of NGOs and the international community during and after the war through development aid, relief, and reconstructions efforts, contributed to internal criticism within the Acholi society that 'have called into question established local belief and value systems' ([7], p. 272). It is not unexpected that many community and cultural leaders in Gulu speak about Acholi society using narratives that highlight change and loss as a threat to traditional values, and the need to continue rebuilding, strengthening and persevering traditional institutions. In these narratives, street youth/children and their current behaviours and attitudes are flagged as a major source of insecurity, undermining both what is seen by many as traditional Acholi values, and as an obstacle to the reconstruction of a society that adhere to those institutions [76]. These tensions coupled with the history of the Aguu and contemporary criminal activities and organisation of some street youth/children, led to labelling of the Aguu as a deviant and disturbing entity by members of the community, the police, and local leaders. Viewing groups such as the Aguu as deviants is not uncommon from criminological perspectives (but also not uncontested within the same discipline). This point of view is expressed from a particular understanding of how society should be in a context by those who have the power to define and sanction, and subsequently lead to explanations of why some members of that society 'deviate' from this 'mainstream' view. As we explained above, the Aguu are viewed as such a deviant group by the police (a law-and-order institution concerned with enforcing the common law of the state of Uganda, tasked with crime reduction), local leaders and members of the community (who mainly view their society through a mixture of their cultural institution, state institutions, the context of the civil-war, and a variety of interests that collide/align with the existence of Aguu, including economic, power, and cultural motives), and within the context of changing urban settings/growth of Gulu. From a theoretical perspective, these entities view the Aguu through a lens of Anomie: the breakdown of norms [77]. Through this lens, transitions in societies are often 
viewed as leading to a crisis of norms for some, caused by the shift/loss of long standing and familiar social institutions, especially when conflict is involved. When this disjunction occurs in societies, many individuals enter a transition period where they find themselves in a state of confusion and disorganisation caused by break down of norms brought about by the loss of their social anchors [78]. Based on this concept, the Strain Theory of Deviance was developed in criminology [79] linking the breakdown of norms to the adoption (by some in society) of nonstandard approaches to life, such as crime, to achieve status and goals in society. Viewed through this lens, the formation of gangs and their criminal activities are often explained as deviant subcultures [80] arguing that while groups as such diverge from accepted social norms, they also create a different sets of norms they develop, and a subculture is formed. This lens is consistent with the predominant view of the Aguu in Gulu as an 'entity' by the police, local leaders, and the community, in an assemblage where these entities are interacting in the space of Gulu city. The context presented here is linked to conflict, post conflict re-construction, growth of the urban space, changing contexts (institutional, cultural, economic etc.) and new opportunities available for everyone. The Aguu and the organisation of criminal groups within them, are viewed by the police, local leaders, and the community as a force of change that collides with predominant views about continuity of specific socio-cultural and state institutions. On the other hand, some of the same individuals who label the Aguu as deviants, see them as an opportunity to achieve political, economic or other objectives. These views of the Aguu as opportunity leads to two main categories of interaction with them. On the one hand the Aguu feature in discourses as a source of insecurity in Gulu by those who have an interest of using the Aguu for purposes of political or economic gains to increase personal or other status. This also leads at times to concrete measures against the Aguu, such as the 'vigilante' acts we describe. On the other hand, various individuals within the police, local leadership and the community, use their various powers to co-opt the Aguu and utilise them for economic gain, as labour, removing economic and political competition, and sorting personal and civic disagreements through violence. Some of these interactions with the Aguu can be analysed from an assemblage perspective as efforts to de-territorialise the group, for example by criminalising the 'entity' and taking actions against them. Other interactions lead to increased territorialisation of the Aguu, for example by mobilising them to achieve economic, political, and civic interests which results in strengthening the organisation and opportunities available to street youth/children. Thus, perceptions of the Aguu go beyond the dissatisfaction of an older generation with the choices of youth in the post-war era; the Aguu are simultaneously viewed as a source of insecurity due to crime and rebellious social behaviours, but also used by the same groups who label them as unwanted deviants to turn profit, to secure interests and for political gain.

In a place where the civil-war is still present in the minds of the population as a cause of contemporary disruption to societal norms, structures and livelihoods, some of the discourses in relation to the Aguu equates them to a dangerous 'rebel group' that pose security threats to the population and the city of Gulu [81-83]. As specified by street youth and various other stakeholders in Gulu, the conflict is still seen as a significant underlying cause for the presence of Aguu in the streets of Gulu. This is not only in relation to the current leadership of some Aguu 'gangs' of which some indicated that they belonged to the original group of street youth/children who found themselves in the streets as a direct result of the conflict.

This is also relevant to youth and children that ended in the streets of Gulu after the end of the conflict for reasons that are described as insecurities affecting caregivers stemming from the conflict, including difficult socio-economic situations, lack of access to livelihood due to loss of land, mental health, and other traumatic effects etc. The conflict is also the main reason behind the accelerated processes of urbanisation, growth and change in Gulu [84]. These processes, which began with the conflict and continued after the conflict as part of reconstruction efforts and the presence of a large number of national and international NGOs', present new opportunities for people, and attract many youth/children as well as adults to the streets of Gulu for a variety of reasons.

As specified above, the Aguu is a reference to a complex entity which is defined externally as a homogenous deviant group. Internally, however, the Aguu is varied, multiple, complex and fluid. Despite being used as a derogatory term by most of those who view them as deviants, many street children/youth refer to themselves as Aguu. Some do so to indicate that they are 'dangerous', and as a consequence are left alone or imagine they gain respect through instilling fear. Others do so to convey an identity or a sense of belonging to an entity that fulfils some institutional functions and is composed of individuals that occupy the same physical and societal space.

In reality, Aguu today is a reference to youth and children that have in common the fact that their umbilical cords to mainstream societal structures have been severed or damaged, willingly or unwillingly. While the data illustrates how a history of displacement has led to the inception of the Aguu in Gulu, the subsequent processes of modification and change of this group represents more than the outcomes of the conflict, but also shifting generational values in Acholi society, and a break-down and reformulation of social, cultural, political and economic interests within the shifting character of urban Gulu after the conflict subsided and to date.

When it comes to the criminal organisation of the Aguu, we have outlined some of the territorialisation processes such as physical space, creation of rules, sanction, symbolic language and leadership. We have also indicated how members of the police, community and local leadership contribute to these territorialisation processes through, for example, bribery of police officers, co-option of criminal 
groups for economic gain, for political gain, and for punishment and revenge purposes, but also through marginalising and labelling the groups as social deviants, which leads to the formation of an identity and a counter movement of territorialisation. We have also alluded to the processes that attempt to de-territorialise the Aguu, expressed through police, political and popular actions and rhetoric against street youth/children. Also mentioned are the processes of deterritorialisation in relation to youth/children breaking away from what is considered normative socio-cultural Acholi institutions as well as state institutions such as law and order, and re-territorialisation in the form of Aguu, which, despite the external derogatory and criminal meaning, has also internal representation of identities stemming from access to and availability of new opportunities, hope for better lives, but also constrained choices, criminal organisation and abusive livelihood contexts. In this case, the study of the historical trajectory behind the creation and evolution of the Aguu and the processes that led to the contemporary outcome of their organisation and presence in the streets of Gulu, becomes an important factor for understanding the long-term effects of societal disruptions and new emerging opportunities for human security/insecurity in Gulu.

Referring to the Aguu today as a criminal entity and in derogatory terms, without distinguishing between the original Aguu, the multiple identities and activities of street youth/children at large in Gulu, processes of change in Gulu, the multiple identities and activities of those who use the Aguu for various purposes etc., leads to treating the Aguu today as an homogenous entity, and subsequently to discourses that point to a surface that looks deviant and criminal, but in reality overlooks complexity, multiplicity and fluidity.

\section{Limitations, Implications and Future Research}

This study is focused on the Aguu, their complex history, current complexity, fluidity, change and evolution, and their place in Gulu. We did not study the Aguu in relation to the history and organisation of other criminal groups in Uganda, urban spaces, or elsewhere in Africa and the world. This article does not deal with street youth in African cities as a phenomenon, although our use of Assemblage Theory may nevertheless be relevant in the study of youth in other African cities to reveal underlying complex societal processes. Instead, the article focuses on street youth/children in Gulu linked to the particular context in Northern Uganda, and the shifting external and internal identities of the group and its members. We focused on fleshing out how children/youth became/become 'Aguu', the meanings of this label, the current organisation of the criminal groups within the Aguu, how the Aguu are viewed, understood and used by various members of the community, police, and local leadership, as well as how street children/youth view themselves and their livelihood contexts. We also highlight how these different identities are integrated into political and security discourses in Gulu. For ethical reasons and limitations of time and scope, we did not speak directly with minors, and did not focus on enlarging the number of respondents but focused instead on key informants and different stakeholders to sample the main discourses and opinions. We hope that the findings of this research will enable various stakeholders in Northern Uganda to better understand the identities of those who are labelled Aguu, the background for their formation as an entity, the mechanisms of transformation, and the linkage to criminal organisation. As the UPF is determined to roll its Community Policing Strategy, this article can provide some of the necessary analysis that may assist in developing more nuanced approaches to street children/youth in Gulu.

\section{Acknowledgments}

This research was funded by the EU Horizon 2020 project ICT4COP: 'Community-Based Policing and Post-Conflict Police Reform'. We would like to thank the EU and the project for providing the funding to conduct this research. We express our gratitude to the project leader, Ingrid $\mathrm{Ny}$ borg for support throughout the research process and for commenting on earlier drafts of this article.

\section{References and Notes}

[1] Where Do You Want Us to Go? Abuses against Street Children in Uganda. New York, NY, USA: Human Rights Watch; 2014. Available from: https://www.hrw.org/report/2014/07/17/where-do-you-want-usgo/abuses-against-street-children-uganda.

[2] As of 1 July 2020, the status of Gulu shifted from a 'Municipality' to 'City'. As such, Gulu is currently the principal city in Northern Uganda.

[3] As referred to by Jimmy Patrick Okema, the Police Spokesperson of the Aswa River Region quoted in: Soft Power News. Gulu: police calls for lasting solution to street goons after murder of Bishop's daughter. Available from: https://www.softpower.ug/gulu-police-calls-for-lasting-solutionto-street-goons-after-murder-of-bishops-daughter/.

[4] Lorenz S. Youth Languages and the Dynamics of Language Change. The story of Aguu and the Acholi Youth Language Leb pa Bwulu. The Mouth: Critical Studies on Language, Culture and Society.

2018;(3):173-182. Available from: ttps://kups.ub.uni-koeln.de/8502/ 1/The_Mouth_3_online.pdf.

[5] While officially the conflict between these two entities is not resolved the hostilities have been displaced and continue outside the borders of Uganda.

[6] As emphasised by Lorenz S. [4], the Aguu was coined by street youth in Gulu as a self-reference.

[7] Vorhölter J. Youth at the Crossroads. Göttingen University Press; 2014. doi:10.17875/gup2014-752.

[8] This research was funded by the EU Horizon2020 project ICT4COP.

[9] This research was conducted before the status of Gulu changed, and the reference to the administrative structures in this article are in line with the status of Gulu as a Municipality.

[10] Deleuze G. A Thousand Plateaus: Capitalism and Schizophrenia. University of Minnesota Press; 1987.

[11] DeLanda M. A New Philosophy of Society: Assemblage Theory and Social Complexity. Continuum; 2006. doi:10.5040/9781472546043.

[12] De Landa M. Assemblage Theory. Edinburgh University Press; 2016. 
[13] Buchanan I. Assemblage Theory, or, the Future of an Illusion. Deleuze Studies. 2017;11(3):457-474. doi:10.3366/dls.2017.0276.

[14] Buchanan I. Assemblage Theory and Method. Bloomsbury Academic; 2021. doi:10.5040/9781350015579.

[15] Abrahamsen R, Williams MC. Security Beyond the State: Global Security Assemblages in International Politics. International Political Sociology. 2009;3(1):1-17. doi:10.1111/j.1749-5687.2008.00060.x.

[16] Abrahamsen R, Williams MC. Security Beyond the State. Cambridge University Press; 2010. doi:10.1017/cbo9780511974441.

[17] Higate P, Utas M. Private Security in Africa: From the Global Assemblage to the Everyday. Zed Books; 2017.

[18] Savage GC. What is Policy Assemblage? Territory, Politics, Governance. 2019;8(3):319-335. doi:10.1080/21622671.2018.1559760.

[19] Crewe D. Assemblage Theory and the Future for Criminology. In: Calster V, editor. New Directions for Criminology Antwerp: Maklu. Maklu, Antwerpen, Belgium; 2014. pp. 39-57.

[20] Crewe D. Gang: Culture. Oñati Socio-legal Series. 2016;6(4):9991015. Available from: https://ssrn.com/abstract=2875344.

[21] Feely M. Assemblage Analysis: an Experimental New-materialist Method for Analysing Narrative Data. Qualitative Research. 2019:20(2):174-193. doi:10.1177/1468794119830641.

[22] Hallsworth S. The Gang and Beyond. Palgrave Macmillan UK; 2013. doi:10.1057/9781137358103

[23] Hallsworth S, Young T. Gang talk and Gang Talkers: A Critique. Crime, Media, Culture: An International Journal. 2008;4(2):175-195. doi:10.1177/1741659008092327.

[24] Patton P. Metamorpho-Logic: Bodies and Powers in A Thousand Plateaus. Journal of the British Society for Phenomenology. 1994;25(2):157-169. doi:10.1080/00071773.1994.11007058.

[25] Richmond MA. "Hostages to both sides": Favela Pacification as Dual Security Assemblage. Geoforum. 2019;104:71-80. doi:10.1016/..geoforum.2019.06.011.

[26] Shand W. Urban Assemblage, Street Youth and the Sub-Saharan African City. City. 2018;22(2):257-269. doi:10.1080/13604813.2018.1451138.

[27] White R. Youth Gangs, Violence and Social Respect. Palgrave Macmillan UK; 2013. doi:10.1057/9781137333858.

[28] Klein MW. Street Gangs and Street Workers. Prentice-Hall Englewood Cliffs, N.J; 1971.

[29] Klein MW. The American Street Gang: Its Nature, Prevalence, and Control. Oxford University Press; 1995.

[30] Decker SH. Life in the Gang: Family, Friends, and Violence. Cambridge University Press; 1996.

[31] Esbensen FA, Huitizinga D. Gangs, Drugs and Delinquency in a Survey of Urban Youth. Criminology. 1993;31(4):565-589. doi:10.1111/j.1745-9125.1993.tb01142.x.

[32] Battin-Pearson SR, Thornberry TP, J Hawkins D, Krohn MD. Gang Membership, Delinquent Peers, and Delinquent Behavior. Office of Juvenile Justice and Delinquency Prevention, U.S. Department of Justice; 1998. Available from: https://www.ojp.gov/pdffiles/171119.pdf.

[33] Hill K, Lui C, Hawkins J. Early Precursors of Gang Membership: A Study of Seattle Youth. Juvenile Justice Bulletin. 2001; Available from: https://www.ojp.gov/pdffiles1/oijdp/190106.pdf.

[34] Thornberry TP, Lizotte AJ, Krohn MD, Smith CA, Porter PK. Causes and Consequences of Delinquency. In: Taking Stock of Delinquency. Springer US; 2003. pp. 11-46. doi:10.1007/0-306-47945-1_2.

[35] Kontos L, Brotherton DC, Barrios L, editors. Gangs and Society. Columbia University Press; 2003. doi:10.7312/kont12140.

[36] The Blackwell Companion to Criminology. In: Colin S, editor. The Blackwell Companion to Criminology. Blackwell Publishing Ltd; 2003. pp. 91-124. doi:10.1111/b.9780631220923.2003.00007.x.

[37] We recognise that on this level, we treat the police, local leadership and communities as homogenous entities in regard to their view of the Aguu as an entity. In reality, each of these entities is an assemblage composed of heterogenous individuals, institutions, physical and symbolic properties etc. Local leaders, for example, include religious leadership, cultural leadership, political leadership, customary leadership, informal leadership etc. It is beyond the scope of this article to nuance the assemblage of each of these entities, and we use key informants as representative of the entity's view of Aguu.

[38] It is important to note that by sui-generis we do not mean to insinuate that the Aguu as street youth/children or as criminal gangs in an urban space is a unique phenomenon in Gulu, Uganda. We allude to the particular trajectory that lead to assemblages and their multiplicity and fluidity. Indeed, research on street youth/children and criminal gangs in African cities and elsewhere in the world indicates many similarities between the criminal behaviour of the Aguu in Gulu and other places in the world, as well as similar mechanisms of interactions in contexts of political economy, post-conflict reconstruction, urbanisation etc. As we specify in the limitations section of this article, we do not engage here in a review and summary of this literature, nor conduct a comparative analysis. Nevertheless, the information in this article can serve those who wish to conduct a comparative analysis of street youth/children and criminal organisation in African cities and elsewhere. For some of the relevant literature on these issue see notes[39-42].

[39] Mitton K. Where is the War? Explaining Peace in Sierra Leone. International Peacekeeping. 2013;20(3):321-337. doi:10.1080/13533312.2013.838391.

[40] Shand W, van Blerk L, Hunter J. Economic Practices of African Street Youth: The Democratic Republic of Congo, Ghana, and Zimbabwe. In: Labouring and Learning. Springer Singapore; 2015. pp. 1-21. doi:10.1007/978-981-4585-97-2 5-1.

[41] Petrus T, Kinnes I. New social Bandits? A Comparative Analysis of Gangsterism in the Western and Eastern Cape Provinces of South Africa. Criminology \& Criminal Justice. 2018;19(2):179-196. doi: $10.1177 / 1748895817750436$.

[42] Hendriks M. The Politics of Everyday Policing in Goma: The Case of the Anti-gang. In: Urban Africa and Violent Conflict. Routledge; 2020. pp. 82-97. doi:10.4324/9780429284397-5.

[43] Nyborg I. Emerging Perspectives on Post-Conflict PoliceCommunity Relations. Journal of Human Security. 2019;15(2). doi:10.12924/johs2019.15020001.

[44] Before the status of Gulu changed from Municipality to City, there were four divisions in Gulu municipality. After July $1^{\text {st }}, 2020$, these division were merged into two: Gulu West and Gulu East.

[45] Kiessling R, Mous M. Urban Youth Languages in Africa. Anthropological Linguistics. 2004;46(3):303-341. Available from: http: //www.jstor.org/stable/30028964.

[46] Nassenstein N, Hollington A. Youth Language Practices in Africa and Beyond. De Gruyter Mouton; 2015. doi:10.1515/9781614518525.

[47] Beall J, Goodfellow T, Rodgers D. Cities and Conflict in Fragile States in the Developing World. Urban Studies. 2013;50(15):3065-3083. doi: $10.1177 / 0042098013487775$.

[48] Branch A. The Political Dilemmas of Global Justice: Anti-Civilian Violence and the Violence of Humanitarianism, the Case of Northern Uganda [PhD Thesis]. Columbia University,; 2007. Available from: https://ci.nii.ac.jp/ncid/BA91027513.

[49] Branch A. Gulu in War... and Peace? The Town as Camp in Northern Uganda. Urban Studies. 2013;50:3152-3167. doi:10.1177/0042098013487777.

[50] Finnström S. Living with Bad Surroundings: War, History, and Everyday Moments in Northern Uganda. Duke University Press; 2008.

[51] Dolan C. Social Torture: The Case of Northern Uganda, 1986-2006. vol. 4. Berghahn Books; 2009.

[52] The Lord's Resistance Army: Myth and Reality. Zed Books; 2010.

[53] The literature indicates that the protected villages were death traps, where social and health conditions kept on deteriorating, and the UPDF presence was inconsistent, allowing the LRA to attack and massacre the dwellers of these camps. Please see references ([50], p. 133) [51].

[54] Branch A. Displacing Human Rights: War and Intervention in Northern Uganda. Oxford University Press; 2012. doi:10.1093/acprof:oso/9780199782086.001.0001.

[55] Mitigating Land Based Conflicts in Northern Uganda. Kampala, Uganda: United Religions Initiative (URI) \& Acholi Religious Leaders Peace Initiative (ARLPI); 2012. Available from: https://www.uri.org/sites/default/files/media/document/2017/ Mitigating\%20Land\%20Book\%20final.pdf.

[56] Chelimo GA. Land Rights in the Context of Post-War Northern Uganda: the Case of Amuru District, Uganda. In: Hintjens H, Maguru JM, Nyakaisiki F, Odong J, editors. Challenging Social Exclusion: Multi Sectoral Approaches to Realising Social Justice in East Africa. Kampala, Uganda: Fountain Publishers; 2015. . 
[57] McElroy T, Muyinda H, Atim S, Spittal P, Backman C. War, Displacement and Productive Occupations in Northern Uganda. Journal of Occupational Science. 2012;19(3):198-212. doi:10.1080/14427591.2011.614681.

[58] Baines E, Rosenoff Gauvin L. Motherhood and Social Repair after War and Displacement in Northern Uganda. Journal of Refugee Studies. 2014;27(2):282-300.

[59] Perrot S. Northern Uganda: A 'Forgotten Conflict', Again? The Impact of the Internationalization of The Resolution Process. In: Allen T, Vlassenroot K, editors. The Lord's Resistance Army: Myth and Reality. Oxford, UK: James Currey; 2010. pp. 187-204.

[60] Falk L, Lenz J, Okuma P. A Study of The Dynamics Behind Child Night Commuting Phenomena in Gulu, Uganda. Red Barnet: Save the Children Denmark; 2004. Available from: https: //resourcecentre.savethechildren.net/node/2373/pdf/2373.pdf.

[61] Kalibala S, Elson L. Protecting Hope: Situation Analysis of Vulnerable Children in Uganda 2009. Population Council. 2010 Dec 5;doi:10.31899/hiv1.1005.

[62] Alessandra A. Protecting the Right to Life of the Internally Displaced: An Examination of Encampment and Its Effects on the Communities in Unyama and Koro Sub-Counties in Gulu District, Northern Uganda [ndependent Study Project (ISP)Collection]; 2016. 2345. Available from: https://digitalcollections.sit.edu/isp_collection/2345.

[63] Atkinson RR. The Roots of Ethnicity: The Origins of the Acholi of Uganda Before 1800. University of Pennsylvania Press; 1994. Available from: http://www.jstor.org/stable/j.ctt17mvh9g.

[64] By this we do not mean to insinuate that the current socio-cultural Acholi institutions and organisation are identical to the pre-war institutions. Nevertheless, it is important to note that there is a strong will within the Acholi people to preserve their cultural heritage and uphold societal norms. These are expressed not only by the attempt to recreate institutions, but also by frequent happenings and celebrations in Gulu that highlight Acholi cultural heritage and organisation.

[65] When the Sun Set we Start to Worry: An Account of Life in Northern Uganda. United Nations Office for the Coordination of Humanitarian Affairs (UNOCHA) \& Integrated Regional Information Networks (IRIN); 2004

[66] Lunde H. Night Commuting in Gulu, Northern Uganda: From Spontaneous Strategy to New Social Institution [MSc Thesis]. Oslo, NO; 2006. Available from: http://urn.nb.no/URN:NBN:no-13589.

[67] Pham P, Vinck P, Stover E. Abducted: The Lord's Resistance Army and Forced Conscription in Northern Uganda. 2007; Available from: https://hhi.harvard.edu/sites/default/files/publications/abductedthe-lords-resistance-army.pdf.

[68] Local Council at the lowest administrative level (level 1).

[69] Police in Gulu still Holding 120 Suspects Arrested Christmas Season. Eagle Online. 2019 Jan 11; Available from: https://eagle.co.ug/2019/01/11/police-in-gulu-still-holding-120suspects-arrested-in-christmas-season.html.

[70] Gulu Cracks Down on Notorious Street Gang. The Daily Monitor. 2019 Jun 29; Available from: https://www.monitor.co.ug/ News/National/Gulu-cracks-down-notorious-street-gang/6883345176646-6rxvgaz/index.html.

[71] Ojara E. In Gulu, Aguu Storm Industrial Area, Demand for
Head of LC1 Chairperson. Acholi Times. 2019 Jun 23; Available from: http://www.acholitimes.com/2019/06/23/in-gulu-aguustorm-industrial-area-demand-for-head-of-lc1-chairman/?fbclid= IwAR3hEtrsEtMM7hVj1mt_ql2bY6XvQcz1Xs9xRMWSrl8v7kf2_ 5OI4SXXcTA.

[72] Ojara E. Gulu Local Leaders Seek Police Protection from Thugs 2019 Jul 7; Available from: http://www.acholitimes.com/2019/07/07/ gulu-local-leaders-seek-police-protection-from-thugs/.

[73] Based on interviews with three LC3 Chairpersons in Gulu that were involved in such actions.

[74] How Criminal Gangs are Terrorising Gulu Residents. The Daily Monitor. 2019 Jun 25; Available from: https: //www.monitor.co.ug/News/National/How-criminal-gangs-areterrorising-Gulu-residents/688334-5171380-ift3us/index.html.

[75] While most of our respondents did not refer to the Aguu with compassion, it is important to note that on social media forums dedicated to discussions on the Aguu in Gulu, one can locate different opinions. For example, one comment in a WhatsApp group in Gulu (dedicated to discussions with opinion leaders on contemporary issues), in a thread discussing the Aguu, one person wrote: 'I think we need to devise a more sober, soft mechanism of dealing with these Aguu, like building for them rehabilitation centres amongst others'.

[76] While this view was expressed to us by community members, leaders and the police in an over-generalised fashion, it is important to note that there are many youth in Gulu who believe that preserving Acholi cultural structure and heritage is imperative, and are participating actively in efforts to revive traditional culture and symbolism.

[77] Durkheim E. The Division of Labour in Society. London, UK: Macmillan; 1984.

[78] Durkheim E. Suicide: A Study in Sociology. London, UK: Routledge; 2002.

[79] Merton RK, Merton RC, Company MP. Social Theory and Social Structure. Free Press; 1968.

[80] Cohen AK. Delinquent Boys: The Culture of the Gang. New York, NY, USA: The Free Press; 1955.

[81] See for example quoting a community leader and the Aswa regional Police spokesman (respectively) for linking B13 to Aguu on: New Media Uganda. Available from: https://www.youtube.com/watch?v= hHuQAwVJ4q0.

[82] See for example quoting a community leader and the Aswa regional Police spokesman (respectively) for linking B13 to Aguu on: New Media Uganda. Available from: https://www.youtube.com/watch?v= $6 j n l 4 U K J x i g$

[83] Okema D. No New Rebel Group in Gulu. PMLDaily. 2019 Jul 20; Available from: https://www.pmldaily.com/news/2019/07/no-newrebel-group-in-gulu-police-disclaims-as-residents-vow-to-lynchsuspected-members.html. The police was quick to denounce the equation of $\mathrm{B} 13$ to a rebel group, highlighting that it is a criminal gang of Aguu operating in the Gulu region.

[84] Some may argue that growth and change may have come to Gulu without the conflict. This is most likely true, nevertheless, in the case of Gulu, de-facto, the trajectory of growth and change occurred in relation to the conflict, see for example Branch [49]. 